\title{
Narrative Ethnographies of Diverse Faculty in Higher Education: "Moral" Multiculturalism among Competing Worldviews
}

\author{
Lynn K. Wilder ${ }^{1}$, David Sanon, Cecil Carter, \& Michael Lancellot \\ Florida Gulf Coast University, Fort Myers, USA
}

\begin{abstract}
Since the Civil Right Movement in the United States, African Americans and other diverse students have forged through "integrated" educational systems to terminal graduate degrees. Some studies suggest racial integration in U. S. schools made White participants less prejudiced toward others, although the data showed that after schooling, many Whites again lived (and still do) in segregated neighborhoods with separation in places of employment, churches, and social groups (Wells, Holme, Revilla, \& Atanda, 2004). One diverse participant in this study asked whether, after decades of integration, there has been any real progress, citing excellent educational experiences with all Black teachers within the all Black schools where he grew up. Is it truly progress for diverse students when they are bussed across town to be treated as minorities in mostly White schools? More diverse students do graduate from college; however, the diversity rate of professors is still abysmal. This study reports the contextual experiences of three African American (one an administrator) and one Latina faculty member with decades of experience in the public educational system and as they engaged in the culture of higher education struggling with a moral multiculturalism - whether worldviews (therefore free speech) could be morally determined and whether they as diverse faculty truly belong and are truly respected.

Keywords: higher education, diverse faculty, multiculturalism, moral, integration, narrative ethnography
\end{abstract}

Proud and elegant cypress trees have a distinctive smell in the grassy, alligator swamps of the Southeast. Brilliant birds rest in the swamp trees and in the coniferous trees and scrub of the flatlands. Sandy soils support orchids, ferns, and a plethora of fruit-bearing trees like pawpaw and prickly pear. Savannas and forest sustain bear, panther, deer, wild hog, and fox as well as raccoon, tiny squirrels, and rabbits. Wear shoes, there are venomous snakes! If lucky, one might spot an Artic tern on its annual migration from the North to the South Pole or back again. Increasingly more diverse students are crossing the wooden boardwalk through this wonderland from the parking lot to the main campus, decked out in short-shorts as they hurry past the water hyacinth and America lotus-laden water gardens to class. Mostly, the weather is hot and humid. The South is notorious for the slave trade which provided workers in the cotton fields before the Civil War. Until integration in the U.S., schools were segregated. Today, many neighborhoods in the South are still segregated.

Integration, affirmative action, and multicultural initiatives first led to the integration of public schools in the United States in the 1970s. According to a study completed by Teacher College faculty (Wells, Holme, Revilla, \& Atanda, 2004) at Columbia University, students were fundamentally changed by the integration experience. Most students in the Columbia study were White. Although impacted positively, participants reported returning to integrated neighborhoods and segregated lives post high school or college. Diversity within unity is promoted by James Banks et al. (2001), father of multicultural education in the U.S., and assimilation and integration of immigrants is somewhat typical; however, some cultures/religions may prefer at least some degree of separation. According to the Pew Research Center (2013), for example, ninety-eight percent of Orthodox Jews in the United States do not marry outside of their culture/religion. Surprisingly, one diverse faculty member in this study-unsolicited-presented some positives of school segregation before integration.

Integration has led to an increase of diverse students attending colleges and universities. Regrettably, the same increase of diverse faculty is not evident in higher education (Karatas \& Oral, 2015). For example, over the past 30 years the number of full-time African American faculty members has increased by a mere one percent (Cooper, 2009). In 2015, the National Center for Educational Statistics (NCES) reported that when all college instructors including adjuncts and part-time professors were counted, $77 \%$ of full-time instructional faculty in higher education were White and $23 \%$ were diverse. However, among full-time professors, $83 \%$ were White (more than twice as many White male full professors as White female full professors) and $17 \%$ were diverse (NCES, 2015). Recruitment and retention of diverse faculty continues to be a goal but not a reality in higher education (Dooley, 2003). Therefore, White faculty members bear the brunt of teaching multicultural principles and working to

\footnotetext{
${ }^{1}$ Professor, Special Education, Florida Gulf Coast University, Fort Myers, USA. E-mail: lwilder@fgcu.edu
} 
recruit diverse faculty until more diverse colleagues enter the field of higher education (Damgaci \& Aydin, 2014).

Various studies have indicated that both diverse faculty in higher education and diverse public school teachers create positive climates for diversity, serve as role models, mentor students, provide emotional support, provide diverse views at their institutions, increase collaboration among colleagues, and effectively teach diverse students (Cora-Bramble, 2006; Subervi \& Cantrell, 2007). The lack of diverse faculty member representation in higher education is said to begin in the "pipeline" with the academic achievement of the ever-growing population of diverse K-12 students in the U. S. and their access to and achievement in higher education (Brice, 2012; Myers \& Turner, 2004). Just 13\% of students earning doctorates in 2014 came from underrepresented groups (McMurtrie, 2016).

\section{Tapping into the pipeline}

In recent years, the local school district, a K-12 school district in Florida with more than 80,000 students, released student demographic information reporting that $51.2 \%$ of all students in the district are ethnically diverse, a minority majority district (The School District, 2011). The number of diverse students is increasing in both Lee County Schools and neighboring Collier County Schools. The latter has more than 60,000 students and has been a minority-majority district for over nine years (Collier County School District, 2014). Poverty and homelessness, tightly entangled with ethnic diversity, is rising sharply among residents in Southwest Florida (Florida Center for Investigative Reporting, 2014; Wilder, Rotz, \& Sonntag, 2010).

Regrettably, if and when diverse students pursue the path of higher education at traditional universities, it is unlikely that they will have as many ethnically diverse peers in higher education as they had in public education. Further, they will have even fewer diverse professors from their ethnic background with whom to share the experience, mentor them, or teach them. The diversity rate of students at one university in Florida is approximately 30\%, lagging behind the diversity rate of children in local public schools by $20 \%$ (College Factual, 2014). In the College of Education, we have less than $20 \%$ diverse faculty and do not meet the $30 \%$ university-wide diversity rate for our teacher candidates. Diverse students attending our university typically do not choose education as a career path.

The existence of the pipeline problem is well referenced in articles, but it is not necessarily conclusively supported by research (The JBHE Foundation, 2002; Yigit \& Citamak, 2012). While researchers acknowledge a problem with recruiting ethnically diverse faculty, it appears that there are qualified diverse individuals with advanced degrees who choose not to pursue a career in academia. An analysis of data by Myers and Turner (2004) suggested that even a large increase in the number of diverse individuals in doctoral programs would only result in a marginal increase in the number of ethnically diverse faculty members in higher education. The researchers concluded only a fraction of diverse individuals with advanced degrees find academic employment to be an attractive option when compared to traditional places of employment.

While colleges and universities argue that there is a lack of qualified minority talent to fill positions, ethnically diverse faculty members suggest that there is a different problem. When diverse faculty members were asked about the underrepresentation of minorities in higher education, their response was that there is a deficiency on the part of universities to recruit and retain diverse faculty into their institutions. More specifically, ethnically diverse faculty members cite a lack of resources such as scholarships, assistantships, and travel monies from the university to support diverse doctorate students in advanced degree programs (Myers \& Turner, 2004; Prater, Cramer, Wilder, \& Carter, 2016; Bittman \& Russell, 2016; Reichert, 2006; Ersoy \& Deniz, 2016: Byker, \& Marquardt,2016; Vega, Yglesias, \& Murray, 2010).

Colleges and universities serious about attracting diverse faculty to their institutions make a commitment to mentor students while they are at the undergraduate and graduate levels. Interviews of participants from the Summer Research Opportunity Program (SROP), a nationally recognized diversity initiative program, revealed several benefits of effective mentoring on diverse student achievement. Several participants felt that mentors played an important role in their scholastic development and their decision to pursue advanced degrees. Further, participants reported feeling more confident about their ability to do graduate level work because their mentors were accessible to help them "demystify" the Ph. D. process (Davis, 2008). Without ongoing support and mentorship for ethnically diverse doctorate students, they may not pursue a career in academia if not exposed to the realities/benefits of academia during their doctoral years. Given our years of experience in higher education in different states and in both private and public universities, we have helped diverse doctoral students conduct research, present papers, and even publish while in school. Students need this exposure if they are recruited into a career in higher education. Despite the benefits of mentoring, some institutions do not provide effective mentoring for doctoral students or even assistant professors, diverse or not, leaving them with feelings 
of not belonging as evidenced in this study and in a previous study (Vázquez-Montilla, Wilder, and Triscari, 2012).

Clearly one's feelings about the institutional climate have an effect on their success in that environment. The pipeline may not be the problem after all, instead, there may be other reasons restricting the flow. Some reasons given are the need for a true commitment to diversity, "tokenism," and feelings of marginalization from within the institution. The underrepresentation may stem more from the climate at higher education institutions than from a lack of qualified individuals (Davis, 2008).

\section{Institutional climate}

Why should White professors be concerned about the underrepresentation of diverse faculty and teacher candidates in higher education (Prater, Wilder, \& Dyches, 2008)? First, diversity is a wellaccepted overarching piece of quality enhancement plans and of the everyday operations of institutions of higher education. The Southern Association of Colleges and Schools (SACS) Position Statement on Diversity (2014, p. 1) includes this:

Diversity is reflected in the student body of an institution, as well as among the faculty, staff, administrators, trustees and other stakeholder groups. It is this exposure to a myriad of cultural backgrounds that enriches the learning and teaching experience. It is this person-centered aspect of education that introduces individuals to the broader society in which higher education operates - supporting sensitivity to such differences as culture, ethnicity, race, religion, international origin, student disabilities, and gender that are subject to the unique mission and culture of each institution.

Diversity is an asset to higher education; promoting diversity is a challenge. It challenges institutions to ensure equal access for equal participation (recruitment), to take measures to successfully teach (retention and graduation), to provide requisite academic support for all students, including those with disabilities, and to adapt teaching and learning styles to meet the needs of a diverse student body. It also presents some unique opportunities for teaching, learning, service, research, professional development and overall social, economic and intellectual growth.

According to our accrediting body, diversity is an asset. One of the outcomes of achieving and embracing diversity in higher education listed in this document is that it "embraces the foundation of a democratic society" (Lafer, 2014; SACS, 2014, p. 2). That is, diversity is the very foundation of a democratic society. Therefore, not only is it an asset, but second, diversity (or multiculturalism) is a moral endeavor at the heart of sustaining our democratic republic and protecting the very lives of some. How is multiculturalism moral?

\section{What is a "moral" multiculturalism?}

Multiculturalism was birthed from an aspiration to right moral wrongs perpetrated in the past toward diverse groups or individuals. It is —ideally — a moral endeavor (Obiakor, 2007; Gay, 2010; Kaya \& Aydin, 2014). Multiculturalism was to be a sanctuary where persecuted minority groups were given a voice and empowered. The expected result of ameliorating knowledge about and empathy for diverse groups, was that prejudice and the perpetration of offenses toward particular groups or individuals would be reduced (see Wilder, 2014 for more information on moral multiculturalism). Professors in colleges of education teach and practice a moral multiculturalism because they believe these beliefs and behaviors make a difference in the lives of largely White teacher candidates as they can improve the academic and behavioral outcomes of their future diverse public school students (Goodlad, Soder, \& Sirotnik, 1990; Obiakor, 2007; Kopish, 2016; Tarman \& Acun, 2010; Tarman, 2016). Wilder (2014, p. 5) explained:

In multiculturalism, moral ideals include: knowledge about and acceptance of minorities, equitable treatment, cultural and language accommodations with exemptions and assistance, representation, and other group-differentiated and individual rights (Song, 2010). Immoral tenets include prejudice, bullying and violence, separation, in-equitability, abuse, neglect, and exclusion. Groups and individuals should be examined to reveal immoral beliefs and practices, so that we can use the information to right wrongs.

But, who will do this examining of groups and worldviews "to reveal immoral beliefs and practices?" Who determines what is moral and what is immoral? Some say morality is intuitive. Is it? The United States decided in Brown vs. the Board of Education (1954) that segregation by race was 
immoral. Yet, one participant in this study queried whether desegregated schools were always an inherently better education for diverse children now feeling culturally lost within majority dominated schools. Is segregation of a group or a worldview ever warranted or even preferable for diverse individuals?

Recent discussions about stemming hate speech on the internet and on college campuses forces multiculturalists to query. What about various worldviews? Communism? Mao Ze Dung killed 40 to 70 million Chinese and Tibetans; Stalin at least 27 million of his own people; and Pol Pot in Cambodia killed about 2 million. These three are in the top ten genocides of all time. Should the worldview of Communism be inspected for moral insolence? Maybe anti-Semitism? Hitler slaughtered 6 million Jews. Radical Islam? Ottomans killed 1.5 million Armenian, German, and Greek Christians and ISIS and other radical groups imprison and behead enemies. What about the KKK and White Supremacists? Fascists?

\section{Worldviews}

Worldviews are composites of sets of beliefs, not all of which pass the three tests for objectivity. First, it must not contradict itself. Second, a worldview will be consistent with the facts. And third, it must have viability, sustainability. Humans create a personal worldview that provides a framework for making judgments. Everyone and every group has worldviews that structure their morality. Just say something one thinks is moral (that's brilliant) or do something to them one considers to be immoral (how dare you ....). One's worldview will be exposed.

There are two prevalent, competing worldviews in academia today. (1) All that matters is observable and measurable and nothing else, even thinking, for some, can be real. This worldview is represented by naturalists, typically in the hard sciences. Is there an objective reality? Naturalists in the hard sciences argue yes, but only what can be measured in the natural world, nothing more. Does an objective reality provide the framework for an absolute morality, a moral multiculturalism?

The second (2) worldview in academia is postmodernism. Everything is relative and knowledge and experience are self-constructed. Social scientists are largely postmodernists; the worldview espoused by most educators. Postmodernists would argue that an objective, shared reality does not exist, and personal worldviews are merely socially constructed. If postmodernity rules, how does one decide what is moral and what is not with competing socially constructed ideals? Does it not behoove multiculturalists to address the moral and the immoral in an objective way? Here's the difficulty in the social sciences: Postmodernism.

\section{Postmodernism}

Postmodernism is characterized by one word-relativism, whether in metaphysics, epistemology, or ethics. Simply, relativism means there are no absolutes, different things are moral for different people given their culture, experience, and a million other factors. The key word is relativism. Humans socially construct their own morality.

The worldview of epistemology began to change from certainty to uncertainty with Immanuel Kant. Once the world was introduced to agnosticism, relativism was the result. Some say as a cultural phenomenon, postmodernism began with Nietzsche in Europe and bled to America later. Postmodernism introduced the idea that not even the sciences or sense perception could be trusted. Knowledge is, for postmodernists, simply a social construction. Definitely John Dewey, the father of modern public school education in the U.S., disavowed moral absolutes in the 1930s. When Abraham Maslow published his famed hierarchy of human needs after WWII, the search for meaning turned inward. Maslow's concept of self-actualization encouraged humans to find their own version of morality; in other words, socially construct their own reality. Social sciences in the U.S. embraced this thinking wholeheartedly, including the field of multiculturalism. The challenge with relativism is, how does one determine what is moral?

To strict postmodernists, it does not matter. Many disengage from arguments about morality because all things are relative to an individual's worldview. Avoid arguments about these topics because they are irrelevant (Berger, 1966). "I believe that" or "I'm not comfortable with that" replaces, "that's true" or "that's just wrong." Obviously, most individuals believe they have some moral yardstick based on personal views to determine which is which. If they, individually or collectively, determine a right and a wrong, then intentional attacks on others based on their "moral" interpretations can be justified. If there is no discernible right and wrong morality as some postmodernists assert, any willful attacks on others are groundless. Yet, we do attack and we think we know . . . (Wilder, 2014)

If every socially constructed worldview intrinsically has equitable value, then there is no moral and no immoral multiculturalism among worldviews. Yet, study participants, who were diverse, had strong opinions about what was right and what was wrong for them personally and for their culture and institutions. 
Two study participants suggested they felt they could not disagree with another ethnically diverse individual's point of view, although they felt some disagreement, even some anger. That anger was evident because they felt the other's point of view was not moral or ethical. But as careful as they believed they had to be in not being completely truthful with non-diverse individuals at the university who were typically in position of power over them, they did not want to appear to disagree with others who were diverse either. One described himself as "an angry Black man" who had experienced probable racial prejudice from university colleagues. The challenges of diverse faculty and administrators in higher education is complex. This complexity compounds the comfort and perhaps the longevity of diverse faculty.

\section{Tenor of diverse faculty/administrators in higher education}

In higher education, administrators have not been successful at increasing the diverse faculty on college campuses until that percentage reflects that of the surrounding communities or even the percentage of diverse students on campus. In fact, over the years largely White institutions of higher education do not appear to have increased their welcome to diverse faculty. Part of this study, predictably, simply corroborated that fact. Diverse individuals working in higher education often do not feel they belong. They are not respected. And their voice as cultural brokers is greatly overworked.

Utilizing themes similar to the Vázquez-Montilla, Wilder, and Triscari (2012) survey of diverse faculty in higher education to advance the professional literature regarding perceptions and experiences of diverse faculty - but this time through ethnographic interviews - the researchers designed, coded, and analyzed this qualitative study. The study reports the contextual experiences of four diverse faculty members over the years as they engaged in the culture of higher education addressing three thematic areas: (1) whether they felt they belonged or fit in, (2) whether or not they felt respected by colleagues and administrators, and (3) whether or not they played roles as cultural brokers in the higher education institutions in which they serve, (4) with an invitation to add anything else they wanted researchers to know. Researchers examined how thematic patterns articulated by these four individuals within a group might be consequential for participation in other groups and situations. The information collected during the course of these ethnographies, shed further light on issues affecting ethnically diverse faculty in higher education.

\section{Research questions}

The following research questions were used to guide the interviews:

1. As a culturally diverse faculty member, how do you feel you belong in your current department/area?

2. As a culturally diverse faculty member, how do you feel you have achieved? How are your achievements recognized or not recognized?

3. As a culturally diverse faculty member, how do you act as a cultural broker?

4. Is there anything else you would like to tell me about your experiences as an ethnically diverse faculty member?

\section{Method: Narrative Ethnography as Inquiry \\ Research design: Narrative ethnography}

The research design that provided the framework for this study is consistent with contemporary qualitative research practice (Creswell, 2006). Researchers used narrative ethnography, a fairly recently emerging methodology in social science (Gubrium \& Holstein, 2008). Narrative ethnography "involves an ongoing attempt to place specific encounters, events and understandings into a fuller, more meaningful context" (Tedlock, 2011, p. 331). The purpose of narrative ethnography is to uncover the rich contexts of life history using narrative resources, environmental context, and the researcher who provides an interpretive perspective (Denzin \& Lincoln, 2011). Researchers sought to understand their participant's voice, their life, and their culture within the university setting (Behar, 2003; Shostak, 2000). Narrative ethnography is a powerful tool to translate life events into rich textual discourse, defining how past experiences occurred and exploring what emotions surface set within a particular culture, community, or historical context.

Often, narrative data revisited by interviewees initiated new lines of inquiry and challenged these research scholars to make connections between "lived experiences, social injustices, larger social and cultural structures and the here and now" (Denzin \& Lincoln, 2011, p. 246). Langellier (2001) believed narrative ethnographers could be the initiators of change, writing, "the wounded storyteller reclaims the capacity to tell, and hold onto their own story perhaps leading to personal emancipation and understanding of their life within a context of time, culture, and space" (p. 146). This study unveiled the mediating aspects of culture which often constrain the lives of individuals and impede social and 
individual change in the university setting. The researchers' telling the stories of marginalized individuals may challenge the complacency of privileged others and motivate their reflection on long held oppressive cultural structures.

\section{Four interviews with diverse faculty}

To better understand the perspectives of diverse participants working in a university setting, researchers conducted ethnographic interviews and observed four faculty/administrators in their professional roles on the campus of a university in the Southeast over the course of three years (20112014). Thus purposive sampling was used to extrapolate data which would help to investigate the central research questions. The site selected was appropriate for the study because the university had predominantly White students and faculty. Three of the participants were African American men who held various positions at the university: assistant professor, associate professor/director of a program, and a university-wide administrator. All of the men had previous experience teaching and/or leading in the K-12 setting prior to working at the university. The fourth participant was a female full professor of Hispanic descent. The interviewees consisted of a White faculty member and two doctoral students, one White and one Black.

\section{Data collection}

The data collected in this study included the data from four extensive ethnographic interviews with participants resulting in narrative ethnographies (Wilder, Vázquez-Montilla, \& Greene, 2016). The one-on-one open-ended interviews took place in the participants' offices at the university and were semistructured to allow for participants to respond to a particular topic and questions freely. Follow-up questions were asked according to the previous information given. In order to triangulate the data within the ethnography, researchers (a) observed the diverse individuals in higher education in their respective roles at the university, (b) analyzed the narrative data, and (c) utilized data from the university climate study in order to take an etic perspective and connect the identified themes and behaviors to the context of the Southern university. These three provide triangulated data for confirmation of themes. Each of the four interviews varied in length between one hour and four hours. The interviews were recorded both with researcher field notes and audio recordings of the interviews that were then transcribed.

\section{Data analysis}

The data were analyzed using a variety of techniques. Interview audio was transcribed and interview notes were typed to allow for ease in analysis. Select words such as respect, belong and others categorized as such as well as other in the texts were highlighted to visually elicit frequency in text. After highlighting, interviewers completed inductive coding to extract and organize the data into larger themes. The researchers explored themes and analyzed similarities and differences between interviews to ascertain a better understanding of participants' perspective relating to their role as diverse members within the higher education institution. Multiple iterative readings of interview transcripts and notes and the typing of transcriptions strengthened the interpretation of results. Information from the interviews was evaluated in light of the both the university climate study and the observation of faculty and administrators in their specific work environment.

\section{Trustworthiness}

Qualitative research raises issues of trustworthiness including credibility, transferability confirmability, and dependability as well as the problems with personal perspective and bias (Murchison, 2010). For improved credibility, this study triangulated three sources of data. For transferability, similar themes emerged from previous studies pointing to some measure of generalized experience among diverse faculty. To address confirmability, researchers transcribed interviews and had interviewees member check the data. Anyone interested in replicating the study should contact the researchers.

\section{Results}

The climate study included all students at the university; this university ranked 460 out of 2475 colleges nationwide and obtained a diversity rating of 75 out of 100 (College Factual, 2014). The university is 34\% diverse. The two largest groups are Hispanic/Latino (19\%) and African American (7\%). Participants in the qualitative portion of the study were African American and Hispanic/Latina (female) for this reason. During the three years of the study and during the climate study, the university president was African American.

Observations were informal and occurred in meetings, classes, and in personal interactions over the three years of the study. Observation notes were compared with interview results. 
Common themes emerged from narrative ethnographic interviews analyses, some interviewees shared artifacts, and themes were correlated with observation data and climate study data. These themes were consistent with themes found in the review of literature which was conducted at the onset of the study. The following quotes and themes which emerged from the data represent a selection of data which most suitably illustrated the perspective of participants. In addition to accepted themes, participants introduced some novel ideas from years of personal observation and reflection.

\section{Respect}

Diverse faculty voices:

1. My dissertation advisor said to me, you keep yourself in the mainstream. I avoid teaching diversity. I wonder why I was asked to teach the diversity course twice now. I don't have background in it. Last spring I taught this diversity course and I taught it once before and once I said a few things about the hood, I am lost. I am not a diversity scholar, but I have been asked to teach the class.

2. I like to think I have something to offer intellectually. I have a lot of experiences, I have studies, done some research, not as much as I would like. When my retirement reception is held, what you are going to hear is that I always dressed well and I was involved in athletics...I think both of those are superficial...I also came here to be a faculty member to teach and do some research and scholarship.

3. With regard to the dress that is how I grew up. Black male teachers wore a coat and tie every day. That is the way they dressed. My professors wore coats and ties every day... When I became a classroom teacher I wore a coat and tie every day. It is just the way I dress, it has nothing to do with making a fashion statement, it is the way I was raised. So that is one of my peeves. I have gotten to the point...I don't want to be remembered because I smile a lot. So that is probably the biggest thing and I don't know if that has anything to do with race or not. Sometimes I wonder, sometimes I do wonder.

\section{Belonging}

A higher education faculty member and a program director shared their experiences:

1. Being a young African-American male I feel that I have to work twice as hard to prove myself and get ahead in the arena in which I work. No one has ever directly said this to me, but I feel that it is a given that comes with the territory.

2. There is always a feeling of having to work harder to prove your expertise. This is not a feeling that is expressed directly, but almost an expectation that you must work harder if you are a minority for people to take you seriously.

\section{Cultural broker}

Higher education administrator, faculty, and the director shared their experiences on serving as cultural brokers at their institution:

1. I am often asked to serve on committees because there are no other minorities available to serve. I look at this in a positive way because these committees are helping me to develop skills and allow me to gain insight into university issues. If I am the only qualified minority from my department that can serve on the committee then I am happy to help, even though it is time consuming.

As far as mentoring minority students, it is something that I enjoy doing. I feel that mentoring students is a way to give back and help students through the college experience. Mentoring is especially useful for first-time in college students that need the additional support to help ensure their success in the college system. Mentoring is something that you do because you want to do it, it is not as highly regarded as research but it is just as important.

2. Mentoring students and serving on committees can sometimes be a double edged sword for minorities in higher education. On one hand there is a feeling of responsibility to help minority students navigate the college system. College can be very difficult for students especially those that lack a support system at home. But on the other hand your work requires a lot of your time especially if you are at a research intensive institution. It often becomes difficult to do both things without feeling swamped with the workload. Likewise, serving as the voice of diversity on a committee helps others to consider things from a different point of view, but this is at the expense of valuable time that could be used on research or professional development.

3. Serving on committees is a necessary part of my job at the university as the Director of Community Outreach. I recall serving on a committee that was planning an event to introduce prospective students to our campus. I recognized that the events would not be attractive to all students, and made suggestions on how we could provide more interesting 
events to attract student interest in the school. I feel that I was able to bring a different voice to the committee which in turn benefited the students attending the event.

Mentoring students is another aspect of my job that helps minority students and any other student that takes advantage of it. I feel that being a minority in higher education gives me the opportunity to help students that are finding their way through the system. Being from the community and growing up in an underserved area I am able to readily relate to students. Unfortunately, due to the amount of time mentoring takes, I could see how it would be difficult to balance the desire to mentor and the pressures of pursuing a career that demands research and other forms of service to advance.

\section{Additional Themes Emerged \\ University efforts to recruit and retain minority students lowers the bar}

A university director shared his experience with an administrator:

1. I recall an instance when I inquired about the low level of minority students in a certain program at the university to a director at the university. They told me that they were not trying to make this a remedial university.

Similar experiences are echoed by a faculty member at the university:

2. There is a mentality on campus that believes that increasing minority students would somehow lower the bar. However we know that this is not the case. A common excuse [in the particular college] is that we cannot get people interested in the program. Unfortunately, nobody is actively working on trying to recruit people of color into the field. If we don't sell the product of the [college], how can we expect people to pursue an interest in the program?

A university administrator shared his/her feelings:

3. I feel that a lot is being done to recruit minority students and faculty. While recruitment is important I think that retention is even more important. It is crucial for colleges and universities to have a system in place to support students, especially minority and low SES students. For example, Xavier College in Louisiana is a prestigious school with a high minority demographic. The school stays on top of students; calling students if they miss classes and offer tutoring to students before they fall behind. Funding in terms of scholarships is also needed since minorities often need financial aid to pay for their schooling. I feel that on a scale of one to ten [university] is doing a four in terms of providing support to minority students.

\section{Things weren't so bad in Historically Black Schools and Colleges before segregation}

1. We had outstanding teachers [Black]... before teacher education schools were a big deal in the HBCUs [historically Black Colleges and Universities], when they went into graduate schools, many could not go into state-supported [teachers' colleges], they had to go to Indiana or Michigan... Take a look at X [Black high school]. There are those who would never send their children to X. It's a very good school with excellent programs.... The schools were a major part of the Black community.

\section{Anger, bias, and keeping your mouth shut}

1. It makes me keep my guard up. I am confident in what I know and can do and I forgive, by the way. But I don't forget. Okay, I don't forget so I keep my guard up....Fool me once, shame on you. Fool me twice, shame on me. I don't allow the same conditions to be recreated. You don't necessarily address it at the time. I don't know if avoid is the word I would use. I just don't let it happen.

2. You can be passionate about your cause but you don't have to display your anger. You don't get mad, you get even, and you don't let them know you get even.

3. The options were either teaching or nursing [like for women in the 60s!]. The brighter Blacks went into one of those two.

4. A Black colleague kept making a point over and over [in faculty meeting] and everyone ignored it, and [someone else] raised [their] hand and said the same thing and it was a wonderful idea... That was an experience I had frequently. I feel nobody listens to me.

5. Teach the children the difference between motor oil and antifreeze so they don't pour the wrong substance in the forklift.

\section{Discussion}

It is a delicate balance between utilizing some measure of objectivity in multicultural research (e.g., elements of the climate study or a survey) and accepting differing socially constructed perspectives (interviews resulting in narrative ethnographies and observations). Each of these sources of data were important in this study for a more broad understanding of and a responsible approach to investigating the contexts of diverse faculty in higher education. A moral multiculturalism suggests that multiculturalists should wrestle with setting moral standards for diversity such as those espoused by UNESCO (2017) and 
determine if a view may be harmful to other individuals or groups. Free speech has been greatly impacted on college campuses recently as administrations struggle with what should be said and what should not be said and what may be moral or immoral.

In this study, narrative ethnographies confirmed and then added depth to the themes that have surfaced in past research. One theme that emerged from the results was the perceived sense of belonging of the participants as members of the larger institution. The interviews touched on experiences related to race and race relations between diverse faculty and their White colleagues. Similar to previous findings (Hughes, Horner, \& Ortiz, 2012), participants in the current study voiced frustrations and concerns about their sense of belonging within the institution. Participants expressed the need to work harder in order to establish themselves and advance to higher positions within the institution. Interestingly, the perceived need to work harder as a diverse professor or administrator was never directly stated to participants, but rather seemed to them like an unwritten expectation of being diverse and working within higher education.

Another theme was a perceived lack of respect from colleagues and administrators, the word being repeated frequently in response to the second part of the second question of inquiry: How are your achievements recognized or not recognized?An additional area where findings were consistent with existing literature was the role of diverse university faculty as cultural brokers. Participants expressed the need to serve on committees and mentor students in addition to the other responsibilities of their primary work (teaching or administrating). While participants recognized the importance of mentoring students, especially diverse students, they also recognized the professional sacrifice incurred as a result of their mentoring efforts. Striking the balance between mentor and role model and advancing professional continues to complicate the realities of minority faculty in higher education (Cooper, 2009; Corona et al, 2017; Edwards, Bryant \& Clark, 2008; Hughes, Horner, \& Ortiz, 2012; Vázquez-Montilla, Wilder, \& Triscari, 2012).

Beyond the guiding questions, additional themes emerged: the perspectives of participants concerning the university's efforts to attract and retain diverse students. Participants expressed that efforts were lacking. One of the participants even named another university's model for attracting and retaining minority students and expressed the importance of university support systems in helping students to succeed. Some administrators were reported to have expressed that recruiting diverse students might somehow lower university standards Overall, there was a sense that people within the university wanted diversity, but at the same time diversity was perceived as a negative by some. The recurrent theme of the critical importance of the recruitment and retention of diverse students was somewhat unexpected, at least in its intensity. The participants in the study all saw value in increasing the number of diverse students and faculty at the university. However, participants believed many obstacles exist which must be addressed before the university can be said to truly embrace diversity.

Additionally, in this study (a) diverse faculty reported probable racial prejudice among colleagues and administrators and their anger over it continued, (b) some diverse faculty members felt they must hang together with other diverse faculty and not openly disagree with each other. In higher education in the United States, racial and ethnic changes may be filtering up to the top, but institutional change is still at a snail's pace.

\section{Implications}

Findings from this study have implications for both university faculty and university leadership. The perspectives from diverse faculty members on feelings of belonging, respect, and role as cultural brokers as well as recruitment of diverse students and faculty and institutional climate for safe and free speech expression, have implications for college systems as a whole. One of the most important for university faculty and administration is the value of seeking out and listening to the voices of diverse individuals. While climate surveys provide a glimpse into the broader state of diversity affairs on Southern university campuses, deeper research is needed to ascertain how diverse groups and individuals have or have not fit into the realm of academia. If higher education institutions are to adjust to the changing demographics of their student bodies in undergraduate and graduate school, then it only seems logical for universities to strongly consider the experiences of diverse faculty while in the "pipeline" and while in academic positions and adjust and change given their suggestions since so few diverse faculty still exist on campuses.

The pressure diverse faculty members feel to balance mentorship and committee involvement with their professional duties is something that should be addressed by their administrators. Since the success of diverse students is beneficial to the overall success of the university, it stands to reason that non-diverse faculty members should be trained to assist with the mentoring of diverse students. For example, training could be provided in culturally responsive mentoring to help build capacity within universities to support the success of all students, without diverse faculty being the few to bear this task. 
A shift toward this type of culturally responsive inclusion and support would require a commitment from university leadership to diversity beyond the typical diversity slogans which have called for diversity often without meaningful action.

Finally, the role of diverse faculty as cultural brokers within the institution demands further investigation. Participants in the study recognized the potential role race played in their experiences interacting with other faculty members within the institution, sometimes in their roles as cultural brokers. While participants were eager to serve the university by being the voice for their culture or race when needed, it should be noted they still felt unsure of their place within the institution. The feeling of having to work harder or of only being remembered for superficial things like dress or smiling - tokenismwere concerns held by participants. Universities will need to rectify these concerns if they are going to draw diverse faculty into the institution.

It all comes down to the perceptions of diverse faculty that others do not respect them as intellectual, talented pieces of a well-oiled university machine. This bottom line issue that must be addressed as universities take climate surveys and diverse voices seriously.

The results of this project on a larger scale could be used by university administrators to create cultural climate change on college campuses. Furthermore, colleges can use the data to begin talking about ways that they can address issues of concern that appear from the data, and work on ways to improve their campuses in that regard. We challenge educators not to think of an educational system in terms of diversity gaps but instead to see opportunity gaps so that more diverse faculty will be walking across the boardwalk over the swamp of opportunity to Southern universities that believe all shareholders truly belong, are highly respected, and are not saddled with undue duties as cultural brokers - universities that provide mentoring for scholarly achievement and, finally, that balance objective standards of diversity for determining moral and responsible actions with varying worldviews and speech options.

\section{References}

Allen, W.R., Epps, E.G., Guillory, E.A., Suh, S.A., Bonous-Hammarth, M. (2000). The black academic: Faculty status among African Americans in U.S. higher education. The Journal of Negro Education, 69(.05), 112-127.

Banks, J., Cookson, P., Gay, G., Hawley, W. D., Irvine, J. J., Nieto, S., Schofield, J. W., \& Stephan, W. G. (2001). Diversity within unity: Essential principles for teaching and learning in a multicultural society. Phi Delta Kappan, 83(3), 196-203.

Behar, R. (2003). Translated woman: Crossing the border with Esperanza's story. Boston: Beacon.

Berger, P. L. (1966). The Social Construction of Reality. New York: Penguin Books.

Bittman, B. L., \& Russell, W. B. (2016). Civic education in united states: A multiple regression of civic education scores from the national assessment of educational progress. Research in Social Sciences and Technology, 1(2), 1-23.

Brice, A. J. (2012). Minority recruitment and retention for universities: Bilingual special education faculty. Multicultural Learning and Teaching, Volume 7, Issue 1, ISSN (Online) 2161-2412, DOI: 10.1515/2161-2412.1100, April 2012

Byker, E. J., \& Marquardt, S. K. (2016). Using critical cosmopolitanism to globally situate: Multicultural education in teacher preparation courses. Journal of Social Studies Education Research, 7(2), 30-50.

Center for Strategic Diversity Leadership \& Change Inc. (2010). Florida Gulf Coast University: Campus climate and culture study. Madison, WI: Williams.

Citamak, Y. \& Yigit, H., I. (2012). From Student's Table to Teacher's Desk. International Journal of New Trends in Arts, Sports \& Science Education, 1(2), 1-7.

College Factual, 2014. Retrieved from: http://www.collegefactual.com/colleges/florida-gulf-coastuniversity/student-life/diversity/

Collier County School District (2014). Retrieved from; http://www.collierschools.com/about/fastfacts.aspx

Cooper, J. (2009). A disturbing trend. Diverse issues in Higher education, 26(9), 20-21.

Cora-Bramble, D. (2006). Minority faculty recruitment, retention and advancement: Applications of a resilience-based theoretical framework. Journal of Healthcare for the Poor and Underserved, $17,251-255$.

Corona, R., Velazquez, E., McDonald, S., Avila, M., Neff, M., Iglesias, A., \& Halfond, R. (2017). Ethnic labels, pride, and challenges: A qualitative study of Latinx youth living in a new Latinx destination community. Journal of Ethnic and Cultural Studies, 4(1), 1-13. 
Creswell, J. W. (2006). Qualitative Inquiry and Research Design: Choosing among Five Approaches. Thousand Oaks, CA: Sage.

Damgaci-Koc, F. \& Aydin, H. (2014). An Analysis of Academicians' Perceptions of Multicultural Education: A Turkish Experience. The Anthropologist, 18(3), 817-833.

Davis, D.J. (2008). Mentorship and the socialization of underrepresented minorities into the professoriate: examining varied influences. Mentoring \& Tutoring: Partnership in Learning, 16(3), 278-293.

Denzin, N. \& Lincoln, Y. ( 2011). The Sage handbook of qualitative research. Los Angeles. CA: Sage.

Dooley, E. (2003). Increasing the number of ethnically diverse faculty in special Education programs: Issues and initiatives. Teacher Education and Special Education, 26(4), 264-272.

Edwards, J. B., Bryant, S., \& Clark, T. (2008). African American female social work educators in predominantly White schools of social work: Strategies for thriving. Journal of African American Studies, 12, 37-49. doi:10.1007/s12111-007-9029-y

Ersoy, E. (2015). Assessment of Adolescent Perceptions on Parental Attitudes on Different Variables. Journal of Education and Training Studies, 3(5), 165-176.

Ersoy, E. \& Deniz, M., E. (2016). Psychometric Properties of the Gifted Students' Coping with Anger and Decision Making Skills Scale. Journal of Education and Practice, 7(15), 121-128.

Florida Center for Investigative Reporting (2014). Retrieved from: http://fcir.org/2012/02/12/povertyhomelessness-rising-sharply-among-florida-students/

Gay, G. (2010). Culturally Responsive Teaching. New York City, NY: Teacher's College Press.

Goodlad, J. I., Soder, R., and Sirotnik, K. (1990). Moral dimensions of teaching. San Francisco: Jossey-Bass.

Gubrium, J. F., \& Holstein, J. A. (2008). Narrative ethnography. In N. Hesse-Biber \& Leavy (Eds.), Handbook of emergent methods (pp. 241-264). New York: Guilford.

Hughes, A.K., Horner, P.S., \& Ortiz, D.V. (2012). Being the diversity hire: Negotiating identity in an academic job search. Journal of Social Work Education, 48(3), 595-612.

Kaya, I. \& Aydin, H. (2014). Pluralism, Multiculturalism and Bilingual Education [Çoğulculuk, Çokkültürlü ve İkidilli Ĕgitim]. Ankara: Ani Press.

Kayes, P.E., \& Singley, Y. (2010). Time for community colleges to lead on diversifying faculty. Diverse Issues in Higher education, 27(17), 18.

Kopish, M. A. (2016). Preparing globally competent teacher candidates through cross-cultural experiential learning. Journal of Social Studies Education Research, 7(2), 75-108.

Lafer, S.(2014). Democratic Design for the Humanization of Education. Journal of Ethnic and Cultural Studies, 1(1), 6-12.

Langellier, K. M. (2001). You're marked: breast cancer, tattoo, and the narrative performance of identity. In J. Brockmeier \& D. Carbaugh (Eds.), Narrative and identity: Studies in autobiography, self, and culture (pp. 145-184). Amsterdam, Netherlands: John Benjamins.

McKinley, B.J. (2003). The implementation of diversity in predominantly white colleges and universities. Journal of Black Studies, 34(1), 72-86.

McMurtrie, B. (2016). How to do a better job of searching for diversity. Chronicle of Higher Education, 63(3), p. A20-A-25.

Murchison, J. M. (2010). Ethnography Essentials. San Francisco: Jossey-Bass.

Myers, S.L., \& Turner, C.S. (2004). The effects of PhD supply on minority faculty representation. The American Economic Review, 94(2), 296-301.

National Center for Educational Statistics (2015). Retrieved from: https://nces.ed.gov/fastfacts/display.asp?id=61

Obiakor, F. E. (Ed.) (2007), Multicultural special education: Culturally responsive teaching. Upper Saddle River, NJ: Pearson Merrill Prentice Hall.

Obiakor, F. E., \& Wilder, L. K. (2003). Disproportionate representation of culturally diverse students in special education: What principals can do. Principal Leadership, 4 (2), 16-21.

Prater, M. A., Cramer, A., Wilder, L. K., \& Carter, N. J. (2016). Diverse teacher candidates' perceptions of and recommendations for a special education preparation program. Multicultural Learning and Teaching, Vol. 11(2), 232-251.

Prater, M. A., Wilder, L. K., \& Dyches, T. T. (2008) Shaping one traditional special educator preparation program toward cultural competence. Teaching Education, 19, 137-151.

Reichert, W.M. (2006). Recruiting \& retaining underrepresented minority doctoral students in biomedical engineering. Liberal Education, 92(3), 52-55.

Shostak, M. (2000). Return to Nisa. Cambridge, MA: Harvard University Press. 
Smith, G. A., \& Cooperman, A. (2013). What happens when Jews intermarry? Pew Research Center. Retrieved from: http://www.pewresearch.org/fact-tank/2013/11/12/what-happens-when-jewsintermarry/

Southern Association of Colleges and Schools (2014). Retrieved from: http://www.sacscoc.org/documents/DiversityStatement.pdf

Subervi, F., \& Cantrell, T., H. (2007). Assessing efforts and policies related to recruitment and retention. Journalism and Mass Communication Educator, 62(1), 27-46.

Tarman, B. (2016). Innovation and education. Research in Social Sciences and Technology, 1(1), 77 97.

Tarman, B. \& Acun, I. (2010). Social Studies Education and a New Social Studies Movement, Journal of Social Studies Education Research. 1(1), 1-16.

Tedlock,B. (2011). Braiding narrative ethnography with memoir and creative nonfiction. In. N. Denzin \& Y. Lincoln (Eds.), The Sage handbook of qualitative research. Los Angeles, CA: Sage.

The JBHE Foundation. (2002). Almost no blacks in academic psychology: Does the pipeline defense hold water? The Journal of Blacks in Higher education, 34, 48-49.

The School District of Lee County. (2011). The school district of Lee County: Cycle 2 enrollment 2010-2011.Retrieved from: http://www.lee.k12.fl.us/info/pdf/Student\%20Diversity\%202010-11.pdf

Thompson, C.J., \& Dey, E.L. (1998). Pushed to the margins: sources of stress for African American college and university faculty. The Journal of Higher education, 69(3), 324-345.

Turner, C.S.V. (2002). Diversifying the faculty: A guidebook for search committees. Washington, DC: Association of American Colleges and Universities.

Turner, C.S.V., Myers, S.L., \& Creswell, J.W. (1999). Exploring Underrepresentation: The case of faculty of color in the Midwest. The Journal of Higher education, 70(1), 27-59.

UNESCO (2017). UN documents gathering a body of global agreements: Universal declaration on cultural diversity. Retrieved from: http://www.un-documents.net/udcd.htm\#2.

Vázquez-Montilla, E., Wilder, L. K., \& Triscari, R. (2012). Ethnically diverse faculty in higher education: Belonging, respect, and role as cultural broker. Multicultural Learning and Teaching. Retrieved from: http://www.degruyter.com/view/j/mlt.2012.7.issue-1/issuefiles/mlt.2012.7.issue-1.xml

Vega, W., Yglesias, K., \& Murray, J.P. (2010). Recruiting and mentoring minority faculty members. New Directions for Community Colleges, 152, 49-55.

Wells, A. S., Holme, J. J., Revilla, A. T., \& Atanda, A. K. (2004). How desegregation changed us: The effects of racially mixed schools on students and society. Retrieved from: http://cms.tc.columbia.edu/i/a/782_ASWells041504.pdf

Wilder, L. K. (2012). White voice in multiculturalism: Belonging, respect, and role as cultural broker. Multicultural Learning and Teaching. Retrieved from: http://www.degruyter.com/view/j/mlt.2012.7.issue-1/issue-files/mlt.2012.7.issue-1.xml

Wilder, L. K., Rotz, E. J., \& Sonntag, A. W. (2010). Addressing homelessness in urban schools. Retrieved from: http://ea.niusileadscape.org/docs/FINAL_PRODUCTS/NIUSI/onpoints/addressing_homelessn ess/addressing_homelessness.pdf

Wilder, L. K., Vázquez-Montilla, E., \& Greene, J. (2016). Introduction to the special issue, Unmasking the faces of diverse university students and professors through narrative ethnography. Multicultural Learning and Teaching, 11(2), p. 151-158. https://www.degruyter.com/view/j/mlt.2016.11.issue-2/issue-files/mlt.2016.11.issue-2.xml

Wilder, L.K. (2014). Reflections on a moral multiculturalism and post-modern thought. In J. Bakken (Ed.), White Voices in Multiculturalism. Boston: Elsevier Science. 